\title{
Literature Review on Hollowing Change and Planning Policy of Traditional Villages
}

\author{
Xinlei Hou, Jingrong Shi \\ College of Urban Planning and Architecture, Southwest Minzu University, Chengdu, China \\ Email: 1483765726@qq.com
}

How to cite this paper: Hou, X.L. and Shi, J.R. (2021) Literature Review on Hollowing Change and Planning Policy of Traditional Villages. Open Access Library Journal, 8: e7812.

https://doi.org/10.4236/oalib.1107812

Received: July 31, 2021

Accepted: August 22, 2021

Published: August 25, 2021

Copyright (C) 2021 by author(s) and Open Access Library Inc.

This work is licensed under the Creative Commons Attribution International License (CC BY 4.0).

http://creativecommons.org/licenses/by/4.0/

\begin{abstract}
In recent years, hollowing has become a major problem in China's rural development. As a typical representative of traditional villages, it is of great academic value and practical significance to study the hollowing problem and related policies. By combing the domestic and foreign literature from 2000 to 2020, this paper expounds the relevant achievements and progress of the research on the hollowing out of traditional villages in China, and points out the existing problems in the research and protection of hollowing out of traditional villages at the present stage, in order to provide reference for future research.
\end{abstract}

\section{Subject Areas \\ Urban Planning}

\section{Keywords}

Traditional Village, Village Hollowing out, Planning Policy, Literature Review

\section{The Introduction}

Traditional villages, also known as ancient villages, refer to the villages that formed earlier and have rich material cultural heritage such as buildings, temples, ancestral halls, pavilions, terraces and pavilions [1]. They have certain historical, scientific, cultural and archaeological values and are coordinated with the surrounding natural environment, bearing certain intangible cultural heritage. Traditional village retains the rich and colorful cultural heritage; it is the embodiment of bearing and the Chinese nation traditional culture important carrier; more and more historians, cultural scholars and sociologists are included in the 
category of academic studies, but with the acceleration of urbanization, more and more traditional hollowing out phenomenon in a village; they disappear. Therefore, it is particularly urgent to pay attention to the protection and development of traditional villages. By reading, summarizing and summarizing relevant literature on the protection and hollowing of traditional villages, this paper expounds the relevant achievements and progress of the research on the protection and hollowing of traditional villages in China at present [2], and points out the existing problems in the research and protection of the hollowing of traditional villages at the present stage, in order to provide reference for future research.

\section{Research on Basic Concepts and Theories}

\subsection{Traditional Villages}

Traditional villages refer to those that were formed earlier, have rich traditional resources, and have certain historical, cultural, scientific, artistic, social and economic values that should be protected. There are differences in concept discrimination, protection value and evaluation criteria between the concept and historical and cultural villages. Traditional villages have the characteristics of living heritage, and the academic circles generally emphasize their original protection. According to the definition of authenticity, there are two important elements in traditional villages [3]. The first is the social factor, which is the life force of traditional villages, and the second is the spatial factor, which is the materialized expression of traditional villages' space.

\subsection{Hollowing out Changes}

In the early stage of research, many scholars mainly defined "over-thinning" as social problems such as population loss and economic recession [4]. With the deepening of the research, the research on "over-thinning" has been further advanced. The definition is no longer limited to the superficial emphasis on population reduction and economic decline but focuses on the essence of "over-thinning"-the fundamental changes in rural social structure caused by urbanization and industrialization. However, a reasonable definition of hollowing should be a theoretical construction based on the explanation of its phenomenon. Traditional studies mainly expound the phenomenon of rural hollowing out from the perspectives of geography and economics.

Domestic understanding of "hollowing out" is divided into several perspectives [5]:

1) From the perspective of geography, it is generally believed that hollow-ness is due to the continuous development of "new villages" in the process of transformation and expansion of the current rural spatial pattern, while the "old villages", as the core of the original villages, are empty and abandoned. Early studies focused on the hollowing out of rural spatial pattern, the hollowing out of rural spatial pattern and the hollowing out of housing, focusing on the discus- 
sion of the characteristics and problems of rural homesite change. Later scholars defined hollow as a special structure layout in rural areas from the perspective of land use, that is, large areas of vacant land appear inside. Some scholars return to the overall space and explore the hollow definition from the village spatial pattern.

2) From the perspective of economics, it mainly focuses on the "population hollow" or "industry hollow" caused by the migration of population and labor resources. From the studies on macro population data, it is found that the rural population showed a historic downward trend, and a large number of rural youth and middle-aged labor force flow into the city, resulting in the hollowing out of the rural population structure. Some researchers also investigated the migrant workers of rural middle-aged and young labor force, and discussed the hollowing of rural resources.

In view of the above literature review results, this paper holds that the hollow is not only fixed in the hollow of rural settlement space and land, but also does not equal the simple rural population outflow and industrial hollow [6]. Secondly, in view of the understanding of "change", most scholars believe that the hollowing change is an overall degradation process of rural regional economic and social functions, which includes both geographical degradation and economic degradation. Therefore, around the phenomenon of hollowing, social or spatial research methods should be adopted to carry out the research on the characteristics, types, distribution forms and other aspects of hollowing.

\section{Research on the Change of Village Hollowing and Protection Policies}

\subsection{The Analysis Characteristics and Meanings of the Village Hollowing}

1) "Hollowing out" of rural Population

In the process of industrialization and urbanization, a large number of farmers have left rural areas and moved to cities and towns. On the one hand, it leads to the decrease of rural regular households and population year by year; On the other hand, as most of the outflow population is young and middle-aged, the elderly, women and children stay at home more, resulting in a serious imbalance of rural population structure.

2) "Hollowing out" of rural Manpower

The phenomenon of "empty shell families", "empty nesters" and "left-behind children" is increasing gradually. In many rural areas, the situation of "no place for the old" and "no place for the young" has appeared to vary degrees. There is a serious shortage of human capital in rural areas, and some kinds of jobs that require strong labor force are not available and cannot be borne. Especially, it is difficult to concentrate manpower to complete such problems as food, clothing, housing, transportation, education, medical care, irrigation and water conservancy construction, rural renovation and rectification, and the construction of 
rural grass-roots Party organizations, which involve the immediate interests of the vast number of farmers.

3) "Hollowing out" of rural housing

The phenomenon of "people leaving houses empty" caused by farmers going out is increasing gradually. The situation of "hollowing out" of housing is complicated. First, some migrant workers and businessmen move to the city with their families after getting a firm foothold, or even turn to urban hukou, leaving the original housing site idle. Second, due to the high urban housing prices, farmers do not have enough economic conditions to take root in the city, they are more inclined to return home to build new houses, and then go out to work; Third, a considerable number of farmers are reluctant to demolish the old house when building new houses, believing that the old house is the symbol of the family or the guarantee of basic life.

\subsection{Related Research Abroad}

Although developed countries do not put forward the concept of hollowing out explicitly, they have also encountered similar problems in the process of urbanization, such as concentration of population and various resources in cities, land wastage, loss of vitality and other rural decline caused by the widening gap between urban and rural areas. At the beginning of the 19th century, sociology and economics began to focus on the study of spatial pattern changes in the process of rural decline. The research on spatial pattern is from the earliest focus on the difference of terrain, industry, to the focus on humanity. The research content is richer and richer, mainly including the morphological characteristics of spatial pattern in different stages and related influencing mechanism. In 1996, Roberts B. K made a great innovation by systematically analyzing the change of rural spatial pattern from prehistory to the present on a large time scale. In the late 1990s, governments of various countries paid more and more attention to rural issues. With the implementation and continuous promotion of LUCC research plan, rural settlements also became a hot spot of rural changes. In the 1990s, inspired by the life cycle theory in economics, related scholars paid attention to the rise and fall of rural settlements. With social development, some rural settlements will continue to decline, while others will gradually develop and grow into central villages, and finally gradually become the center of a small region. The rise and fall of rural settlements are due to the rapid progress of urbanization. The migration of population, adjustment of industrial structure, transformation of lifestyle and transformation of village functions brought about by urbanization have an impact on the land use of rural settlements in different types of villages (PakM, 1998). In 2004, through the study of the change process of rural settlements in the suburbs of Poland, we enriched the explanation of the mechanism behind the change of rural settlements. Some Western scholars believe that the change process of rural settlements is essentially. A process of game among various stakeholders, and the interests of each stakeholder are jointly in- 
fluenced by various aspects such as property rights system and government management mode. In 2005, American scholars studied the change rate and impact of rural settlements in the United States and believed that the continuous expansion of rural settlements had adverse effects on the ecosystem.

In the study of coping strategies to solve the problem of rural hollowing out and decline, developed countries have taken different measures according to their national conditions. In 1984, the United States established a special research institute called "Rural Center" to solve the special problems such as hollowing out faced by traditional villages. Through "suburban construction", it increased the efforts of rural construction and policy inclination to solve the problem of rural decline. In order to change the situation of severe urban crowding and severe poverty in traditional villages, India launched a nationwide "Rural Comprehensive Development Campaign" in the 1980s to alleviate rural poverty and stop the outflow of population from traditional villages. During the 70s and 1960s, Japan and South Korea respectively by "traditional village" and "movement" have unified the traditional village infrastructure and environment construction and renovation, to improve the production and living conditions of farmers, promote the development of social economy, the traditional village Britain through the construction of the "central village", To alleviate the urban and rural contradictions in the process of urban construction and rural population decline, rural construction nobody. Typical examples include the "new traditional village Movement" in South Korea, the "traditional village consolidation" in Japan and the "central village construction" in Britain, which can be used for reference in the governance of rural hollowing in China. However, their rural social attributes are different from those in China.

\subsection{Domestic Related Studies}

1) Research on hollowing of traditional villages

The change of rural hollowing has attracted the attention and research of many scholars in the 1990s, but most of them focus on ordinary villages, few of which take traditional villages as an example. Traditional villages are special to ordinary villages because of their rich material and intangible heritage. The research on hollowing of traditional villages is mostly put forward as the problem of the decline of traditional villages.

a) Understanding of "change": Due to the limitations of rural data, there are few diachronic empirical studies on "village hollowing" in the academic circle, and more scholars have described the characteristics and spatial distribution patterns of different stages of rural hollowing. Many scholars, according to the development of "hollow village", such as the proportion of new apartments, the characteristics of the village, the old and new indices such as the layout of the housing and housing vacancy rate, the formation of the hollow village can be divided into early, middle and late three development stages.

b) Research on the spatial distribution of rural hollowing: Due to different 
perspectives, most scholars draw different conclusions. Some researches focus on the distribution of vacant houses in the spatial pattern, and discuss the form of distribution. The distribution of vacant houses in the spatial pattern is divided into three forms: "point-like" distribution, "block-like distribution" and "plane-like" centralized distribution. The stress behind spatial pattern was explored, and the hollowing spatial pattern was divided into three spatial forms: "ring", "fan" and "ribbon".

c) Research on the intergenerational succession of rural hollowing: Attention to the differences of intergenerational succession and scholars, based on the "rural hollowing out" intergenerational succession space forms of analysis and research, found that as the third generation, the fourth generation of housing construction has developed, and the first generation and second generation of rural homestead "abandoned" was significantly intensified, eventually leading to the village general form within the "real" "poached egg" the structural.

Most of the above researches focus on the traditional villages in the inland plains and mountain areas, but there are a few of research on the plateau traditional villages in minority areas. The hollowing problem faced by traditional villages in minority areas is different from that in plain areas, but relevant researches are scarce.

2) Research on coping strategies of hollowing out in traditional villages

The research on coping strategies of hollowing is carried out from macro and micro levels such as system, infrastructure and employment. Different scholars have different views on cause analysis and put forward different strategies.

a) Industry: Planning and design strategies of activation, transformation, transformation and rebirth are proposed for the hollowing out of traditional villages.

b) In terms of architecture: strategies and specific implementation methods are also proposed from the perspective of architectural renovation; In addition, from the perspective of land integration, the investigation and evaluation of land consolidation potential of hollow villages should be carried out to tap the potential of land consolidation of rural construction land, especially rural residential land, and propose different integration modes.

c) Economic: According to economic geographers, residential vacancy is closely related to the failure of land planning regulatory departments. So long as government agencies take their duties seriously, the logic goes, hollowing out can be avoided. Economists generally think this is the result that rural economy did not adjust in time, it is a kind of economic phenomenon.

As you can see, the occurrence of scholars for hollowing out principle multiple lineage functional idea, the understanding of rural hollowing out phenomenon for us to provide the beneficial research for reference, however, they invariably simplicity is always in the pursuit of theory, focuses on attribute data and the physical form, give up the whole understanding of the mechanism behind the social form. 


\section{Conclusions}

To sum up, both domestic and foreign researches on the changes of rural hollowing have made certain breakthroughs, and rich theoretical researches have been carried out on the definition, characteristics, types and distribution forms of rural hollowing. It can be said that hollowing has been a commonplace topic, but in recent years, with the acceleration of urbanization and the proposal of rural revitalization strategy, this issue has been paid more attention to by the academic community. However, although many scholars have analyzed and studied village hollowing in various ways, some aspects are still lacking:

\subsection{The Relevant Literature Is Prone to Fall into the Trap of "Discussing Space in Terms of Space or Population in Terms of Population"}

In the process of rural modernization, the mode of production has changed and the population has been lost. Social relations also split, mutate or disappear rapidly, which leads to the rapid proliferation, fragmentation, migration, renewal, integration or abandonment of the living space, thus contributing to the gradual evolution of the village from the community state to the hollowing state.

\subsection{There Is a Lack of Quantitative Research for Planning Technicians to Control the Change of Village Hollowing}

Due to the limitations of rural data, there are few quantitative studies on the change of "village hollowing" in the academic circle at present. More scholars have qualitatively elaborated the characteristics and spatial distribution of "rural hollowing" in different stages. The formation of hollowing needs a process. In different stages of its change, the degree of hollowing and its internal form are different. However, most people describe the phenomenon and characteristics, analyze problems and study specific villages at the present stage, and most of them are "basic data-current situation investigation-Qualitative analysis-subjective evaluation". However, there is a lack of objective indicators to evaluate the degree of hollowing of rural villages, including traditional villages. Even if some scholars pay attention to this point, they can only establish a model evaluation through land geographic information and related indicators. The lack of quantitative research will further lead to the lack of coping strategies for hollowing changes.

\subsection{The Research on Hollowing of Traditional Villages Is Insufficient}

With the acceleration of urbanization, the influence of modernity and the loss of population, traditional villages are facing the danger of disappearing. Traditional villages have certain historical, cultural, scientific, artistic, social and economic values, carry regional culture with regional and national characteristics, and present different regional differences and characteristics. The hollowing problem faced by traditional villages is more complex than that of ordinary villages. But 
throughout the relevant literature, most of the research is on the villages in the general plain area, and there is still a blind spot in the study of traditional villages.

\section{Funding}

This paper is supported by Southwest Minzu University's Innovative Research Project for Postgraduates in 2021 (No. CX2021SP156).

\section{Conflicts of Interest}

The authors declare no conflicts of interest.

\section{References}

[1] Luo, P.J. and Zheng, Y.A. (2020) Visual Study on Literature Review of Chinese Traditional Village Tourism Development Based on CiteSpace. Geography and Geo-Information Science, 36, 129-135.

[2] Chen, Y. (2017) Review on Archival Preservation of Traditional Village Culture in China Based on Knowledge Graph. Beijing Archives, 13, 14-18.

[3] Li, L.M., Guo, Y.Q. and Song, P. (2020) Using CiteSpace to Review the Research on Traditional Architectural Villages in China in Recent Ten Years. Southern Architecture, $25,35-40$.

[4] Huang, Y., Chen, C. and Zhang, Q.-P. (2019) Analysis of Knowledge Map of Chinese Traditional Village Research Based on CSSCI Database. Packaging Engineering, 40, 281-289, 297.

[5] Yang, G.Q., Kai, X., Song, D.J., et al. (2018) Exploring the Way of Living Regeneration of Traditional Villages-A Case Study of Wuyantou Ancient Village in Huangyan, Zhejiang Province. Southern Architecture, 30, 49-55.

[6] Qu, X.S. and Zhang, D.P. (2017) The Impact of Tourist Perceived Value and Local Identity on Civic Behavior in Traditional Villages. Enterprise Economy, 40, 123-131. 